\title{
Strategi Humas KPU Bea dan Cukai Tipe A Tanjung Priok dalam Mengelola Media Sosial Instagram
}

\author{
Belinda Nathania ${ }^{1}$, H.H Daniel Tamburian ${ }^{2 *}$ \\ ${ }^{1}$ Fakultas Ilmu Komunikasi, Universitas Tarumanagara, Jakarta \\ Email: nathaniabelinda88@gmail.com \\ ${ }^{2}$ Fakultas Ilmu Komunikasi, Universitas Tarumanagara, Jakarta* \\ Email:danielt@fikom.untar.ac.id
}

Masuk tanggal : 15-12-2021 revisi tanggal :06-01-2022, diterima untuk diterbitkan tanggal : 16-01-2022

\begin{abstract}
Public Relations is an important part for organizations or companies, because the activities carried out by PR practitioners aim to build and maintain the company's brand image so that it remains good in the eyes of the community. In providing understanding to the community, there must be a party who has the responsibility for providing the information, which connects the community with the public. Those parties are none other than public relations or public relations practitioners. Alongside the mindfulness that advertising assumes a significant part in building the picture of the organization, the presence of public relations in Customs and Excise is also felt as a necessity that must be prioritized. Public Relations of Customs and Excise continues to play a role in strengthening relations with the community through the execution of strategy social identified with customs and extract. To speak with the general population, Customs and Excise's public relations are also closer to each other through the media, either through advertisements, online media, or by giving data on the latest customs developments. The theory utilized in this examination is public relations theory, public relations strategy, and social media. This research utilizes enlightening subjective research strategies by gathering information as meetings, documentation, and observations.
\end{abstract}

Keywords: customs and excise, public relations, social media

\begin{abstract}
Abstrak
Humas merupakan bagian penting bagi organisasi ataupun perusahaan, karena kegiatan yang dilakukan oleh praktisi Humas bertujuan untuk membangun serta menjaga brand image perusahaan agar tetap baik dimata masyarakat. Dalam memberikan pemahaman kepada masyarakat, harus ada pihak yang memiliki tanggung jawab atas pemberian informasi tersebut, yang menghubungkan antara masyarakat dengan publiknya. Pihak tersebut tidak lain tidak bukan adalah praktisi public relations atau humas. Seiring dengan kesadaran bahwa humas memegang peranan yang penting dalam membangun citra organisasi, keberadaan humas di Bea Cukai juga dirasakan sebagai suatu kebutuhan yang harus diutamakan. Public Relations Bea Cukai berperan terus mempererat hubungan dengan masyarakat melalui pelaksanaan sosialisasi-sosialisasi kebijakan yang berkaitan dengan kepabeanan dan cukai. Untuk berkomunikasi dengan publiknya, public relations Bea Cukai juga mendekatkan diri melalui media, baik melalui iklan, media sosial, ataupun dengan menyediakan informasi mengenai perkembangan bea cukai terbaru. Teori yang digunakan dalam penelitian ini adalah teori humas/Public Relations, strategi humas, dan media sosial. Peneltian ini menggunakan metode penelitian deskripsif kualitatif dengan mengumpulkan data berupa wawancara, dokumentasi, dan observasi.
\end{abstract}

Kata Kunci: bea dan cukai, humas, media sosial 


\section{Pendahuluan}

Pada zaman sekarang, masih banyak masyarakat awam yang belum mengerti pentingnya informasi mengenai bea cukai. Apalagi bagi mereka yang jarang atau belum pernah berpergian menggunakan pesawat terbang atau keluar masuk bandara. Bea Cukai merupakan organisasi yang berperan penting dalam membangun nasional dan perlindungan stakeholder. Bea dan Cukai memiliki tanggung jawab atas segala hal yang berkaitan dengan bea dan cukai. Kepabeanan dan Perpajakan memegang peranan yang sangat penting untuk menjauhi Indonesia dari barang-barang berbahaya dan merusak berbagai sistem bernegara dan kehidupan. Sebagai lembaga penting dalam perdagangan internasional, peran bea cukai semakin meningkat sebagai salah satu faktor dalam memajukan perdagangan. Menurut Rosady Ruslan (2016) perencanaan strategi dalam Public Relations melibatkan pembuatan keputusan tentang tujuan dan sasaran program, mengidentifikasi publik kunci, menentukan kebijakan atau aturan untuk memandu pemilihan strategi, dan menentukan strategi.

Dalam memberikan pemahaman kepada masyarakat, harus ada pihak yang memiliki tanggung jawab atas pemberian informasi tersebut, yang menghubungkan antara masyarakat dengan publiknya. Pihak tersebut tidak lain tidak bukan adalah praktisi Public Relations atau humas. Humas adalah karakter yang sangat penting untuk menaikan citra yang positif, humas di Bea dan Cukai juga merupakan suatu kepentingan yang harus diutamakan. Hal ini dapat dilihat dengan adanya berbagai macam hal yang telah dilaksanakan di tim humas dalam perusahaan maupun organisasi.

Sarana komunikasi publik yang saat ini paling popular sehingga mampu memberikan informasi secara luas melalui media sosial. Salah satu media yang biasa dipergunakan untuk melakukan komunikasi dengan jarak yang jauh, proses interaksi antar pemakai dan pengumpulan informasi melalui aplikasi khusus menggunakan internet. Tujuan dari jejaring sosial itu sendiri adalah menjadi alat komunikasi untuk menghubungkan pengguna dengan pengguna lain dalam skala besar.

Di masa pandemi Covid-19 ini Bea Cukai sulit untuk memberikan informasi secara langsung terhadap stakeholder. Sejauh ini masyarakat Indonesia belum mengenal atau mengetahui keberadaan sosial media Instagram Bea Cukai. Maka itu Penulis akan meneliti bagaimana strategi yang digunakan Humas di Kantor Pelayanan Utama Bea dan Cukai Tipe A Tanjung Priok dalam mengeola media sosial yaitu Instagram untuk memberitahu informasi-informasi mengenai Kepabeanan kepada masyarakat Indonesia.

Rumusan masalah dari penelitian ini adalah bagaimana strategi Humas KPU Bea dan Cukai Tipe A Tanjung Priok dalam mengelola media sosial Instagram. Tujuan terhadap penelitian ini adalah untuk mengetahui bagaimana penyusunan strategi Humas Bea dan Cukai Tipe A Tanjung Priok dalam perencanaan (planning), pengorganisasian (organizing), pengimplementasian (directing), pengendalian (controlling) untuk mengelola media sosial Instagram.

\section{Metode Penelitian}

Penelitian ini berdasarkan pada penelitian kualitatif. Menurut Sugiyono (2015) ata kualitatif adalah data yang berupa kalimat, kata, dan gambar. Data kualitatif berupa uraian komentar pengamat terhadap kinerja dosen dan pelajar selama proses pembelajaran dan komentar pengamatan terhadap rencana kinerja pembelajaran yang 
akan dilihat dosen atau peneliti. Berdasarkan pendekatan tersebut, jenis penelitian yang digunakan adalah pendekatan deskriptif kualitatif.

Penelitian pada peneliti Metode ini menggunakan metode deskriptif kualitatif. Menurut Sugiyono (2016), metode deskriptif kualitatif adalah metode penelitian yang didasarkan pada filosofi post-naturalisme. Bertujuan untuk mengecek situasi objek yang alamiah yang artinya penelitian ini adalah sebuah kunci terhadap cara pengumpulan data yang dilakukan dengan menghubungkan, analisis data ini bersikap kualitatif, dan kesudahan dari penelitian kualitatif lebih menunjukan makna dibandingkan dengan generalisasi.

Penelitian deskriptif kualitatif ini bertujuan untuk menerangkan, memberikan penggambaran, memberikan penjelasan, memberikan arti dan memberi jawaban secara terperinci masalah akan digali dengan cara mempelajari individu, kelompok atau peristiwa sebesar mungkin. Dalam penelitian kualitatif, orang adalah instrumen penelitian, dan hasilnya dicatat dalam bentuk kata-kata atau pernyataan yang sesuai dengan keadaan yang sebenarnya. Oleh sebab itu, peneliti memilih metode deskriptif kualitatif dalam penelitian ini untuk mengetahui strategi yang digunakan KPU Bea dan Cukai Tipe A dalam mengelola media sosial Instagram dan peneliti akan menganalisis pesan dalam wawancara yang akan peneliti lakukan.

Berdasarkan pada pengumpulan data secara kualitatif, sangatlah penting untuk melakukan suatu metode pengumpulan data. Berdasarkan pada acuan metode penelitian kualitatif, dikatakan bahwa Teknik mengumpulkan data adalah langkah yang sangat tepat dalam meneliti karna tujuan pertama dari penelitian adalah untuk memperoleh data. Dilihat dari beberapa sumber data, pengumpulan data dapat dikategorikan menjadi dua sumber, yaitu penggunaan primer dan sumber sekunder. Metode yang peneliti gunakan terhadap metode pengumpulan data sebagai berikut: observasi, wawancara dan dokumentasi. Penelitian ini sudah melaksanakan wawancara dengan tiga narasumber Kantor Pelayanan Utama (KPU) Bea dan Cukai Tipe A Tanjung Priok yang menjadi triangulasi sumber peneliti.

\section{Hasil Temuan dan Diskusi}

\section{Peran Humas KPU Bea dan Cukai Tipe A Tanjung Priok Dalam Mengelola Media Sosial Instagram}

Berdasarkan hasil wawancara dengan Muchammad Iqbal Anindita, Pipen Dewantoro Wibowo dan Rifat Reyhansyah, peran Humas di Bea dan Cukai sangat penting untuk membangun citra yang positif dan membangun reputasi yang baik terhadap masyarakat dan juga berperan sebagai ujung tombak lembaga dalam membangun citra dan menunjukkan eksistensi terhadap stakeholder, baik dalam skala nasional maupun internasional.

Dengan cara Humas Bea dan Cukai melayani masyarakat dan memberikan Informasi-informasi dan aturan baru terkait Bea dan Cukai di Media sosial Instagram. Dengan adanya Media Sosial Instagram ini mempermudah Humas untuk memberikan informasi yang ingin di beritahukan kepada stakeholder atau pengguna jasa.

Tidak hanya memberikan informasi Humas Bea dan Cukai juga memperluas pengetahuan terkait Kepabeanan Bea dan Cukai untuk masyarakat. Sehingga peran Humas sangat penting bagi KPU Bea dan Cukai Tipe A Tanjung Priok. 


\section{Strategi Humas KPU Bea dan Cukai Tipe A Tanjung priok Dalam Mengelola Media Sosial Instagram}

Berdasarkan hasil wawancara dengan Muchammad Iqbal Anindita dan Pipen Dewantoro Wibowo dan Rifat Reyhansyah, strategi yang digunakan Humas KPU Bea dan Cukai Tipe A Tanjung Priok dalam mengelola media sosial Instagram yaitu dengan mengikuti perkembangan zaman atau trending yang sedang memuncak di masyarakat.

Dengan strategi ini Humas Bea dan Cukai membuat desain grafis semenarik mungkin dengan mengikuti trend zaman sekarang, yang bertujuan membuat stakeholder tertarik untuk melihat dan menyukai postingan-postingan yang ada di media sosial Instagram Bea dan Cukai Tipe A Tanjung Priok.

Salah satu strategi yang disebutkan oleh narasumber yaitu lelang otomotif, dengan adanya lelang ini tim Humas mencoba untuk memposting story di media sosial Instagram dengan mention para influencer otomotif maupun youtuber sehingga dari lelang ini followers bertambah naik. Tidak hanya posting kegiatan atau aktivitas, tim Humas juga memberikan Informasi mengenai aturan-aturan baru di Bea dan Cukai, dengan adanya perkembangan zaman sekarang tim Humas Bea dan Cukai Tanjung Priok membuat media sosial Instagram.

Dan juga tim Humas KPU Bea dan Cukai Tipe A Tanjung Priok mengelola media sosial Instagram dengan melakukan multiple cross check untuk tiap bahan atau pengumuman yang akan diunggah di semua media sosial, dalam hal ini instagram, sehingga apa yang diberikan kepada masyarakat adalah info yang akurat.

Selain itu Humas KPU Bea dan Cukai Tipe A Tanjung Priok memiliki strategi Golden Hour untuk mengunggah konten, arti dari Golden hour ini adalah memposting konten di jam tertentu yang mempunyai engagement tinggi yang dapat dilihat dari fitur Insight di media sosial Instagram.

\section{Simpulan}

Berdasarkan dari hasil penelitian mengenai strategi humas KPU Bea dan Cukai Tipe A Tanjung Priok dalam mengelola media sosial Instagram dapat di simpulkan Strategi yang digunakan humas KPU Bea dan Cukai Tipe A Tanjung Priok dalam mengelola media sosial Instagram adalah dengan cara mengikuti perkembangan zaman atau trending yang sedang memuncak, dengan membuat desain grafis semenarik mungkin untuk di postingkan di media sosial Instagram @beacukaipriok dan juga melakukan multiple cross check untuk tiap bahan atau pengumuman yang akan diunggah di semua media sosial.

Dengan strategi ini humas KPU Bea dan Cukai Tipe A Tanjung Priok memberikan informasi terkait peraturan terbaru kepada stakeholder melalui media sosial Instagram, dengan mengikuti perkembangan zaman dan membuat desain grafis yang menarik perhatian stakeholder sehingga stakeholder dapat memahami dan membaca informasi yang diberikan dengan saksama.

Dengan strategi ini, humas mendapatkan banyak followers yang mengikuti Instagram @beacukaipriok, salah satu strategi yang digunakan humas KPU Bea dan Cukai Tipe A Tanjung Priok dengan mengadai lelang otomotif yang di acarai di Instagram @beacukaipriok sehingga menarik stakeholder untuk melihat dan menambah followers pada Instagram @ beacukaipriok. 
Belinda Nathania, H.H Daniel Tamburian: Strategi Humas KPU Bea dan Cukai Tipe A Tanjung Priok dalam Mengelola Media Sosial Instagram

\section{Ucapan Terima Kasih}

Penulis ingin mengucapkan terimakasih kepada narasumber yang telah bersedia menjadi informan dari penelitian ini. Penulis juga berterima kasih kepada dukungan setiap pihak, mulai dari Fakultas Ilmu Komunikasi Universitas Tarumanagara, sampai seluruh rekan yang membantu jalannya penelitian ini hingga akhir.

\section{Daftar Pustaka}

KPU BC Tipe a tanjung priok. KPU BC TIPE A TANJUNG PRIOK. (n.d.). Diakses pada 13 Oktober 2021. http://bcpriok.beacukai.go.id.

Primansyah, E., Nisyak, H., \& Murti, K. (2021). Strategi Humas Kantor Wilayah Direktorat Jenderal Bea Dan Cukai Sumatera Bagian Timur Dalam Mensosialisaikan Program "Gempur Rokok Ilegal" (skripsi). Universitas Sriwijaya.

Ruslan, Rosady. (2010). Kiat dan Strategi Public Relations. Jakarta: PT Raja Grafindo Persada.

Ruslan, Rosady. (2016). Manajemen Public Relations dan Media Komunikasi: Konsepsi dan Aplikasi. Jakarta : Rajawali pers

Sugiyono. (2015). Metode Penelitian Kombinasi (Mix Methods). Bandung: Alfabeta

Sugiyono. (2016). Metode Penelitian Kuantitatif, Kualitatif dan R\&D. Bandung: PT Alfabet. 